A small sample of the amine is allowed to react with $1: 2: 4$-fluorodinitrobenzene and the dinitrophenyl-derivative is identified by reversed-phase chromatography on paper. In a typical experiment, fluorodinitrobenzene $(0.15 \mu \mathrm{l}$.) in $0.2 \mathrm{ml}$. of ethanol was added to $10 \mu \mathrm{gm}$. of the amine or its hydrochloride in $0.1 \mathrm{ml}$. water, followed by $0.2 \mathrm{~N}$ sodium bicarbonate solution $(0.1 \mathrm{ml}$.). After standing for $15 \mathrm{~min}$. at room temperature, the solution was placed at $105^{\circ}$ in a sealed tube for $2 \mathrm{hr}$. Excess fluorodinitrobenzene was removed by addition of a solution of glycine $(0.1 \mathrm{ml}$. containing $300 \mu \mathrm{gm}$.) and allowing the mixture to stand for $2 \mathrm{hr}$. at room temperature ${ }^{\circ}$. Ethanol was then removed in a vacuum dosiccator, $0.15 \mathrm{ml}$. of $0.2 \mathrm{~N}$ sodium bicarbonate solution added and the dinitrophenyl-amines extracted into ether. The residue obtained on evaporation of the ether solution was dissolved in $5 \mu \mathrm{l}$. ethanol and $1 \cdot 7 \mu \mathrm{l}$. of the solution applied to a paper chromatogram. Whatman No. 1 paper treated with Dow Corning silicone No. $1107^{7}$ was used and the chromatograms were developed with the more polar phase obtained on mixing methanol, chloroform and water $(10: 10: 6$ by volume). The chromatograms were run as recommended by Kritchevsky and Tiselius ${ }^{7}$ and allowed to develop for $16 \mathrm{hr}$., when the solvent front had run off the bottom of the sheet (35 cm. long). 2:4-Dinitroaniline $\left(R_{F}, 0 \cdot 60\right)$ had then travelled $26 \cdot 25 \mathrm{~cm}$. The values of $R_{A}$. (defined as the ratio of the distance moved by the substance to the distance moved by 2 : 4-dinitroaniline) and of $R_{F}$ for the dinitrophenylderivatives of the amines used are shown in Table 1 .

Table 1. Behayiour of Dinitrophenyl-Amines on Paper CHROMATOGRAMS

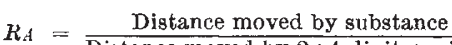

$R_{A}=\frac{\text { Distance moved by } 2: 4 \text {-dinitroaniline }}{\text { Distan }}$

\begin{tabular}{|c|c|c|}
\hline Dinitrophenyl-derivative of & $R_{A}$ & $\boldsymbol{R} F$ \\
\hline Ammonia & 1.00 & 0.60 \\
Methylamine & 0.88 & 0.53 \\
Dimethylamine & 0.80 & 0.48 \\
Ethylamine & 0.67 & 0.40 \\
isoPropylamine & 0.47 & 0.28 \\
Diethylamine & 0.44 & 0.26 \\
isoButylamine & 0.33 & 0.20 \\
isoAmylamine & 0.20 & 0.12 \\
isoHexylamine & 0.12 & 0.07 \\
\hline
\end{tabular}

By plotting the values of $R_{M}\left[=\log _{10}\left(\frac{1}{R_{F}}-1\right)\right]$

for the dinitrophenyl-derivatives of the primary and secondary amines against the number of methylene groups in the amines, two parallel straight lines are obtained for the two homologous series (cf. BateSmith and Westall ${ }^{8}$ ).

With the small spots applied to the chromatograms, all the dinitrophenyl-amines listed are separated from each other except the derivatives of isopropylamine and diethylamine. These two substances can be separated by prolonged development of the chromatogram. The spots can easily be eluted from the appropriate areas of the chromatograms with $3 \mathrm{ml}$. of ethanol. Measuroment of the optical density of the resulting solutions at $345 \mathrm{~m} \mu$ shows that the primary and secondary amines used have reacted almost quantitatively with 1:2:4-fluorodinitrobenzene. Ammonia gives only about 50 per cent of the expected yield and the high temperature used for the reaction is required to obtain this yield. The low solubility of the dinitrophenyl-derivative of methylamine in ethanol may also result in low recoveries in certain cases. Where an elongated spot due to dinitrophenyl-methylamine will not interfere with other substances, the spots may be applied to the chromatogram in ethanol-acetone $(1: 1)$ instead of ethanol. The theoretical recovery of dinitrophenylmethylamine is then obtained. The method therefore appears to have potentialities as a semi-quantitative tool.

Since the dinitrophenyl derivatives of the primary aliphatic amines show an absorption maximum at $345 \mathrm{~m} \mu$, while the corresponding derivatives of secondary amines show a maximum at $365-370 \mathrm{~m} \mu$, the measurement of the optical density of an eluate at two wave-lengths provides corroborative evidence as to whether the substance is derived from a primary or secondary amine.

Sir William Dunn School of Pathology,

I. M. LOCKHART University of Oxford.

$$
\text { Oct. } 26 .
$$

${ }^{1}$ Sanger, F., and Thompson, E. O. P., Biochem. J., 53, 353 (1953). 2 Lockhart, I. M., Abraham, E. P., and Newton, G. G. F., Biochem. J. $[61,534(1955)]$.

\& Bremner, J. M., and Kenten, R. H., Biochem. J., 49, 651 (1951).

- Dougall, D., and Abraham, E. P., Nature, 176, 256 (1955).

- Schwyzer, R., Acta Chem. Scand., 6, 219 (1952).

Grassmann, W. Hormann, H., and Endres, H., Ber. Dtsch. Chem. Ges., 86, 14777 (1953).

'Kritchevsky, T. H., and Tiselius, A., Science, 114, 299 (1951).

Bate-Smith, E. C., and Westall, R. G., Biochim. Biophys. Acta, 4, 427 (1950).

\section{Erosion in Meanders}

IN connexion with the communication by $\mathrm{J}$. $\mathbf{H}$. Horlock in Nature of November 26, p. 1034, I am writing to urge that the term 'meander' should be strictly limited to natural meanders, not to bends due to secondary flows. The term 'meander' is derived from the River Meander, which swings from bank to bank in an almost perfect pattern. The Central Board of Irrigation, India ${ }^{1}$, many years ago defined "a meandering river as a river which follows a sinuous path due to natural physical causes, not imposed by external restraint". The experiments quoted were carried out under very unnatural conditions and hence produced highly unnatural results.

\section{C. Inglis}

Hydraulics Research Station,

(Director) Howbery Park, Wallingford, Berks.

"See "The Behaviour and Control of Rivers and Canals (with the aid of Models)"; obtainable from Publications Branch, General Department, India House, Aldwych, W.C.2. 138.

I AM grateful to Sir Claude Inglis for pointing out that the term 'meander' should be restricted to bends similar to natural meanders. I agree that the initial shapes of the bends used in the experiments described in my communication were not true meanders; but the point of the experiment was to demonstrate that the nature of the erosion in such bends would depend largely on the initial curvature at entry to the bend. Such artificial bends probably develop into natural meanders. Subsequent experiments on natural meanders of similar amplitude and wave-length show that erosion occurs on the banks on the outside of the bends, and not on one bank, as in the original experiments with artificial bends.

Engineering Laboratory,

$$
\text { J. H. HoRLOCK }
$$

Cambridge. 